http://jurnaltarbiyah.uinsu.ac.id/index.php/raudhah

e-mail: jurnalraudhah@uinsu.ac.id

p-ISSN: 2338-2163

e-ISSN: $2716-2435$

\title{
Pengaruh Permainan Congklak dan Gatheng Terhadap Kecerdasan Logika Matematika Anak Usia Dini di RA Khairu Ummah
}

\author{
${ }^{1}$ Yusnaili Budianti \\ Universitas Islam Negeri Sumatera Utara \\ email: yusnailibudianti@uinsu.ac.id \\ ${ }^{2}$ Enny Nazrah Pulungan \\ Universitas Islam Negeri Sumatera Utara \\ email: pulunganennynazrah@gmail.com \\ ${ }^{3}$ Indah Nuraini \\ Universitas Islam Negeri Sumatera Utara \\ email: indahnurainitan@gmail.com
}

\begin{abstract}
Article received : 25 November 2020
Review process : 8 Januari 2021

Article accepted : 10 Februari 2021

Article published : 8 Maret 2021
\end{abstract}

\begin{abstract}
Abstrak
Penelitian ini bertujuan untuk mengetahui pengaruh permainan congklak dan gatheng terhadap kecerdasan logika matematika anak usia dini di RA Khairu Ummah. Penelitian ini berjenis penelitian kuantitatif Pre-Experimental Design. Sampel pada penelitian ini yaitu 30 orang anak yang terdistribusi pada dua kelas, yaitu kelas Matahari yang menggunakan permainan congklak dan kelas Melati yang menggunakan permainan gatheng. Penelitian ini menggunakan teknik pengumpulan data berupa observasi terstrukur. Teknik analisi data yang digunakan yaitu uji hipotesis menggunakan rumus uji-t, dan uji prasyarat analisis menggunakan rumus uji normalitas liliefors dan uji homogenitas fisher. Penelitian ini membuktikan bahwa: (1) ada pengaruh permainan congklak terhadap kecerdasan logika matematika anak usia 5-6 tahun di RA Khairu Ummah; (2) ada pengaruh permainan gatheng terhadap kecerdasan logika matematika anak usia 5-6 tahun di RA Khairu Ummah; dan (3) terdapat perbedaan pengaruh antara permainan congklak dengan permainan gatheng terhadap kecerdasan logika matematika anak usia 5-6 tahun di RA Khairu Ummah.
\end{abstract}

Kata kunci: anak usia dini; kecerdasan logika matematika; permainan congklak; permainan gatheng

\begin{abstract}
This study aims to determine the effect of congklak and gatheng games on mathematics logic intelligence in early childhood at RA Khairu Ummah. This research is a quantitative PreExperimental Design research. The sample in this study were 30 children who were distributed in two classes, namely the Matahari class which used the congklak game and the Melati class which used the gatheng game. This study uses data collection techniques in the form of structured observation. The data analysis technique used is the hypothesis test using the t-test formula, and the prerequisite analysis using the Liliefors normality test formula and the Fisher homogeneity test. This research proves that: (1) there is an effect of congklak games on the logical intelligence intelligence of children aged 5-6 years at RA Khairu Ummah; (2) there is an effect of playing
\end{abstract}

Pengaruh Permainan Congklak dan Gatheng Terhadap Kecerdasan Logika Matematika Anak Usia Dini di RA Khairu Ummah

Copyright (c) 2021 Budianti, Pulungan, Nuraini 
http://jurnaltarbiyah.uinsu.ac.id/index.php/raudhah

gatheng on the logical intelligence intelligence of children aged 5-6 years at RA Khairu Ummah; and (3) there is a difference in the effect of congklak games with gatheng games on the mathematical logic intelligence of children aged 5-6 years at RA Khairu Ummah.

Keywords: early childhood; mathematical logic intelligence; congklak game; gatheng game

\section{A. PENDAHULUAN}

Berdasarkan kenyataan yang terjadi di lapangan bahwa guru yang memberikan pembelajaran untuk meningkatkan kecerdasan logika matematika anak tidak sesuai dengan tahapan usia anak sehingga membuat anak jenuh, bosan dan bahkan mengabaikan pembelajaran, karena media yang digunakan kurang menarik bagi anak. Juga kurangnya minat anak terhadap permainan yang diberikan oleh gurunya, kurangnya pengetahuan guru terhadap metode permainan yang dapat meningkatkan kecerdasan logika matematika anak. Jadi, salah satu permainan yang dapat digunakan dalam peningkatan kecerdasan logika matematika anak di RA Khairu Ummah yaitu permainan congklak karena permainan ini dapat membantu anak belajar berhitung.

Permainan yang diberikan harus mempunyai makna untuk anak, seperti melalui permainan tradisional. Dalam permainan tradisional tidak hanya menstimulus perkembangan fisik anak saja, tetapi seluruh aspek perkembangan atau kecerdasan dapat di stimulus melalui permainan tradisional ini seperti kecerdasan logika matematika, linguistic, interpersonal, intrapersonal, kinestetik, visual spasial, music, naturalistic, dan kecerdasan spiritual. Peran guru dan orang tua sangat penting dalam memfasilitasi kebutuhan anak guna membantu dalam meningkatkan seluruh aspek perkembangannya.

Salah satu permainan yang dapat digunakan dalam peningkatan kecerdasan logika matematika anak di RA Khairu Ummah yaitu permainan congklak karena permainan ini dapat membantu anak belajar berhitung dengan senang, tidak cepat bosan, tidak cepat lelah. Permainan congklak diberikan agar anak dapat melakukan eksplorasi terhadap apa yang dilakukannya saat bermain sehingga anak dapat menghitung, mengetahui angka, mengetahui penjumlahan, banyak dan sedikit. Permainan ini akan menambahkan semangat anak karena menarik. 
http://jurnaltarbiyah.uinsu.ac.id/index.php/raudhah

Dari uraian di atas, maka dilakukan penelitian dengan judul permainan congklak dan gatheng terhadap kecerdasan logika matematika anak usia dini di RA khairu ummah. Adapun beberapa masalah yang menjadi pertanyaan penelitian yaitu:

1. Apakah terdapat pengaruh permainan congklak terhadap kecerdasan logika matematika anak usia 5-6 tahun?

2. Apakah terdapat pengaruh permainan gatheng terhadap kecerdasan logika matematika anak usia 5-6 tahun ?

3. Apakah ada perbedaan permainan congklak dengan permainan gatheng terhadap kecerdasan logika matematika anak usia 5-6 tahun?

\section{B. METODE PENELITIAN}

Penelitian ini dilakukan di RA Khairu Ummah yang beralamat di Jalan Masjid Dusun IV Desa Purwodadi Kecamatan Sunggal, Kota Medan. Penelitian dilaksanakan pada semester genap tahun ajaran 2019/2020. Penelitian ini merupakan penelitian kuantitatif dengan desain Pre Experimental Design. Menurut (Maisarah, 2019; Sugiyono, 2017) Preexperimental design merupakan penelitian eksperimen yang belum sungguh-sungguh karena masih terdapat variabel lain yang mempengaruhi tetapi tidak diteliti. Salah satu tipe pada desain penelitiannya yaitu: One Group Pretes-Postest yang menerapkan hanya satu treatment, namun pada penelitian ini memodifikasi tipe tersebut menjadi dua buah treatment pada sampel yang berbeda sehingga bagan desain berubah seperti penelitian (Maisarah, 2016) yang disajikan pada Tabel 1:

Tabel 1. Desain Penelitian

\begin{tabular}{|c|c|c|c|}
\hline Kelas & Pre-test & Treatment & Post-test \\
\hline Eksperimen 1 & $\mathrm{O}_{1}$ & $\mathrm{X}_{1}$ & $\mathrm{O}_{2}$ \\
\hline Eksperimen 2 & $\mathrm{O}_{3}$ & $\mathrm{X}_{2}$ & $\mathrm{O}_{4}$ \\
\hline
\end{tabular}

Keterangan:

$\mathrm{X}_{1}$ : permainan congklak

$\mathrm{X}_{2}$ : permainan gatheng

Pengaruh Permainan Congklak dan Gatheng Terhadap Kecerdasan Logika Matematika Anak Usia Dini di RA Khairu Ummah 
http://jurnaltarbiyah.uinsu.ac.id/index.php/raudhah

$\mathrm{O}_{1}$ : pre-test kecerdasan logika matematika (sebelum menggunakan permainan congklak

$\mathrm{O}_{2}$ : post-test kecerdasan logika matematika (sebelum menggunakan permainan congklak $\mathrm{O}_{1}$ : pre-test kecerdasan logika matematika (sebelum menggunakan permainan gatheng) $\mathrm{O}_{2}$ : post-test kecerdasan logika matematika (sebelum menggunakan permainan gatheng)

Dari uraian di atas, maka penelitian ini membutuhkan dua sampel yang menggunakan treatment berbeda. Populasi dari penelitian ini yaitu seluruh anak usia 5-6 tahun di RA Khairu Ummah sebanyak 42 orang yang terdistribusi pada tiga kelas, yaitu: 15 orang anak di kelas Matahari, 15 orang anak di kelas Melati, dan 12 orang anak di kelas Mawar. Sampel pada penelitian ini yaitu dua kelas sehingga dipilih kelas yang jumlah siswanya sama banyak yaitu kelas Matahari dan kelas Melati.

Teknik pengumpulan data pada penelitian ini yaitu observasi terstruktur dengan menggunakan instrumen lembar observasi dan rubrik penilaian. Teknik analisis data yang digunakan yaitu uji hipotesis menggunakan uji-t.

\section{HASIL TEMUAN DAN PEMBAHASAN}

Data yang ada pada penelitian ini telah dikumpulkan dengan menggunakan teknik observasi. Lembar observasi yang telah disusun akan digunakan untuk mengamati data tentang kecerdasan logika matematika anak. Pada saat kegiatan berlangsung, anak-anak diobservasi dengan menggunakan instrumen yang sudah dipersiapkan sebelumnya hal ini bertujuan untuk mengetahui bagaimana gambaran tentang data dan hasil observasi yang dilaksanakan, maka kegiatan dilakukan pada kelas Matahari yang berjumlah 15 anak dan pada kelas Melati berjumlah 15 anak. Kelas Matahari menggunakan permainan congklak di dalam proses pembelajaran, dan di kelas Melati menggunakan permainan gatheng di dalam proses pembelajaran.

\section{Hasil Observasi Pada Kelas Matahari}

Hasil yang diperoleh dari kegiatan observasi tentang kecerdasan logika matematika anak dengan menggunakan permainan congklak pada anak usia 5-6 tahun di RA Khairu Ummah disajikan pada Tabel 2:

Pengaruh Permainan Congklak dan Gatheng Terhadap Kecerdasan Logika Matematika Anak Usia Dini di RA Khairu Ummah 
http://jurnaltarbiyah.uinsu.ac.id/index.php/raudhah e-mail: jurnalraudhah@uinsu.ac.id

p-ISSN: 2338-2163

e-ISSN: $2716-2435$

Tabel 2. Hasil Observasi Kecerdasan Logika Matematika di Kelas Matahari

\begin{tabular}{|c|c|c|}
\hline No & Pre-test & Post-test \\
\hline A01. & 12 & 24 \\
\hline A02. & 12 & 24 \\
\hline A03. & 12 & 24 \\
\hline A04. & 12 & 25 \\
\hline A05. & 13 & 25 \\
\hline A06. & 13 & 25 \\
\hline A07. & 13 & 25 \\
\hline A08. & 13 & 26 \\
\hline A09. & 14 & 26 \\
\hline A10. & 14 & 27 \\
\hline A11. & 14 & 27 \\
\hline A12. & 15 & 28 \\
\hline A13. & 15 & 28 \\
\hline A14. & 16 & 28 \\
\hline A15. & 16 & $\mathbf{2 6}$ \\
\hline Jumlah & $\mathbf{2 0 4}$ & $\mathbf{3 9 0}$ \\
\hline Rata-rata & $\mathbf{1 3 , 6}$ & $\mathbf{2 6}$ \\
\hline Modus & $\mathbf{1 2 ~ d a n ~ 1 3}$ & \\
\hline Median & & 13 \\
\hline
\end{tabular}

Pada tabel 2 diketahui bahwa hasil observasi pada kegiatan permainan congklak pada pre-test di kelas Matahari telah diperoleh nilai yang rata-rata 13,6 dengan nilai yang terendah ialah 12 dan nilai yang paling tinggi ialah 16. Sedangkan pada modus ialah 12 dan 13, dan mediannya adalah 13, kemudian kegiatan permainan congklak pada post-test di kelas Matahari diperoleh nilai yang rata-rata 26 dengan nilai yang terendah 24 sedangkan nilai tertingginya 28, dengan modus 28 dan mediannya 26.

Pengaruh Permainan Congklak dan Gatheng Terhadap Kecerdasan Logika Matematika Anak Usia Dini di RA Khairu Ummah 
http://jurnaltarbiyah.uinsu.ac.id/index.php/raudhah e-mail: jurnalraudhah@uinsu.ac.id

p-ISSN: 2338-2163

e-ISSN: $2716-2435$

\section{Hasil Observasi Pada Kelas Melati}

Hasil yang diperoleh dari kegiatan observasi tentang kecerdasan logika matematika anak dengan menggunakan permainan gatheng pada anak usia 5-6 tahun di RA Khairu Ummah disajikan pada Tabel 3:

Tabel 3. Hasil Observasi Kecerdasan Logika Matematika di Kelas Melati

\begin{tabular}{|c|c|c|}
\hline No & Pre-test & Post-test \\
\hline B01. & 6 & 15 \\
\hline B02. & 6 & 15 \\
\hline B03. & 6 & 15 \\
\hline B04. & 6 & 15 \\
\hline B05. & 7 & 16 \\
\hline B06. & 7 & 16 \\
\hline B07. & 7 & 16 \\
\hline B08. & 8 & 17 \\
\hline B09. & 8 & 17 \\
\hline B10. & 8 & 17 \\
\hline B11. & 8 & 18 \\
\hline B12. & 9 & 18 \\
\hline B13. & 9 & 18 \\
\hline B14. & 9 & 19 \\
\hline B15. & 10 & 19 \\
\hline Jumlah & 114 & 251 \\
\hline Rata-rata & 7,6 & 16,73 \\
\hline Modus & 6 dan 8 & 15 \\
\hline Median & 8 & 17 \\
\hline
\end{tabular}

Pada tabel 3 diketahui bahwa hasil observasi pada kegiatan permainan gatheng pada pre-test telah memperoleh nilai yang rata-ratanya 7,6 dengan nilai terendah 6 dan nilai tertinggi 10. Sedangkan pada modus adalah 6 dan 8 , dan mediannya 8 , kemudian kegiatan 
http://jurnaltarbiyah.uinsu.ac.id/index.php/raudhah

e-mail: jurnalraudhah@uinsu.ac.id

p-ISSN: 2338-2163

e-ISSN: $2716-2435$

permainan gatheng pada post-test di kelas Melati diperoleh nilai yang rata-ratanya 16,73 dengan nilai yang terendah 15 sedangkan nilai tertingginya 19, dengan modus 15 dan mediannya 17.

\section{Perbandingan Nilai Pre-test Kecerdasan Logika Matematika Anak Usia 5-6 Tahun di Kelas Matahari dan Melati}

Data pret-test pada kedua kelas dibandingkan untuk mengetahui kecerdasan awal yang dimiliki anak. Kecerdasan logika matematika anak yang menggunakan permainan congklak di kelas Matahari memperoleh nilai rata-rata pre-test sebesar 13,6 atau berkategori mulai berkembang (MB), sedangkan anak yang menggunakan permainan gatheng di kelas Melati memperoleh nilai rata-rata pre-test sebesar 7,6 atau berkategori mulai berkembang (MB). Dengan demikian, terlihat bahwa kecerdasan logika matematika pada kelas yang berbeda mempunyai kategori perkembangan awal yang sama yaitu mulai berkembang (MB). Perbandingan nilai pre-test kecerdasan logika matematika anak usia 56 tahun di kelas Matahari dan Melati disajikan pada Tabel 4 dan Gambar 2:

Tabel 4. Data Pre-test Kecerdasan Logika Matematika di Kelas Matahari dan Melati

\begin{tabular}{|c|l|c|c|}
\hline No & \multicolumn{1}{|c|}{ Statistik } & Kelas Matahari & Kelas Melati \\
\hline 1. & N & 15 & 15 \\
\hline 2. & Jumlah Skor & 204 & 114 \\
\hline 3. & Rata-rata & 13,6 & 7,6 \\
\hline 4. & Simpangan Baku & 1,403 & 1,298 \\
\hline 5. & Varians & 1,971 & 1,685 \\
\hline 6. & Maksimum & 16 & 10 \\
\hline 7. & Minimum & 12 & 6 \\
\hline
\end{tabular}

Pengaruh Permainan Congklak dan Gatheng Terhadap Kecerdasan Logika Matematika Anak Usia Dini di RA Khairu Ummah 
http://jurnaltarbiyah.uinsu.ac.id/index.php/raudhah

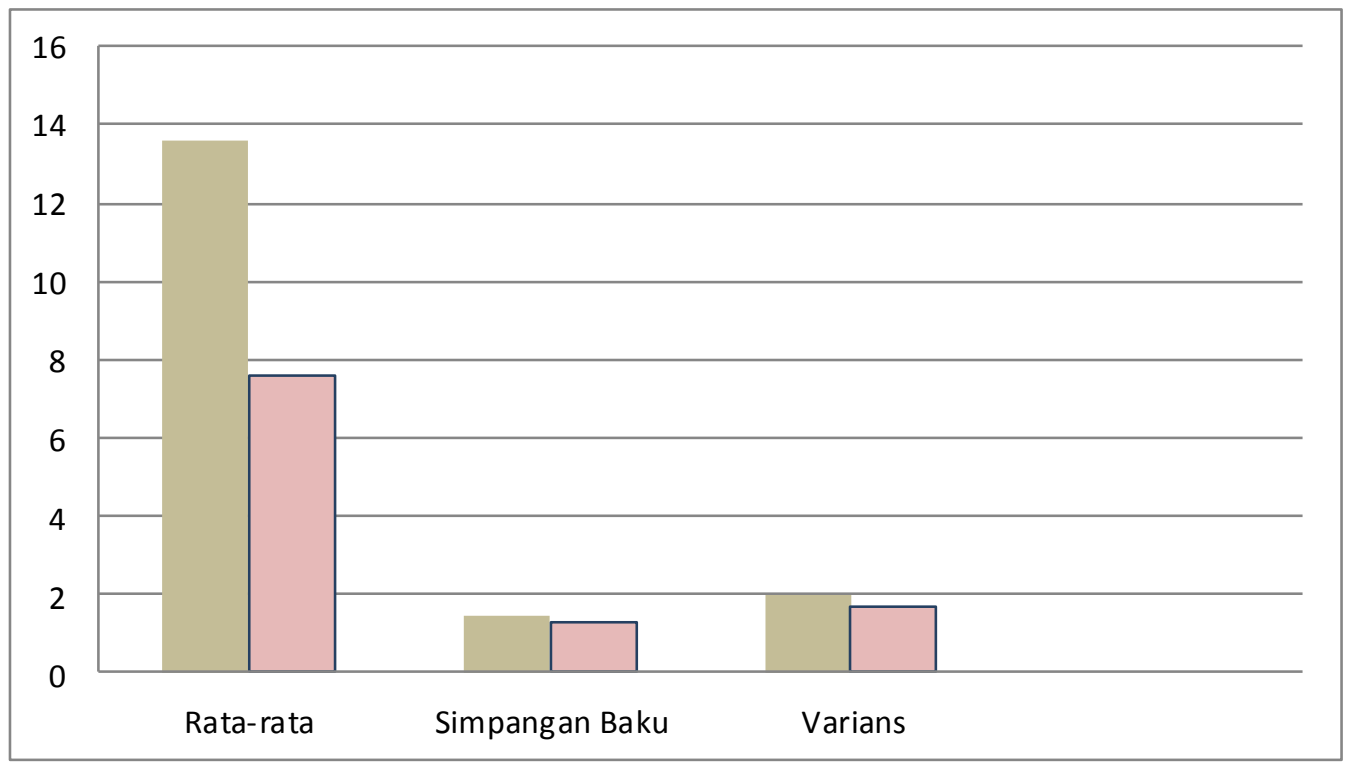

\section{Gambar 2. Data Pre-test Kecerdasan Logika Matematika di Kelas Matahari dan Melati}

Tabel 4 menunjukkan bahwa nilai rata-rata di kelas Matahari yaitu 13,6 atau berkategori mulai berkembang (MB) sedangkan di Kelas Melati yaitu 7,6 atau berkategori mulai berkembang (MB), selisih rata-rata pada dua kelas tersebut sebesar 5,0. Simpangan baku di kelas Matahari yaitu 1,403 sedangkan di kelas Melati yaitu 1,298, selisih simpangan baku pada dua kelas tersebut hanya sebesar 0,105. Varians di kelas Matahari yaitu 1,971 sedangkan di kelas Melati 1,685, selisih varians pada dua kelas tersebut hanya sebesar 0,286. Dari gambar 4 juga terlihat bahwa nilai simpangan baku dan varians pada kelas Matahari dan Melati mempunyai tinggi yang hampir sama, namun pada nilai rata-rata terlihat perbedaan tinggi yang mencolok karena selisih nilainya yaitu 5,0. Perbedaan tinggi batang diagram dan nilai rata-rata kecerdasan logika matematika belum membuktikan perkembangan awal yang berbeda. Hal tersebut karena kedua kelas memperoleh kategori kecerdasan logika matematika yang sama yaitu mulai berkembang (MB). Oleh karena itu, untuk mengetahui kenormalan data, hingga pengaruh dari permainan terhadap kecerdasan logika matematika anak usia 5-6 tahun harus dianalisis mendalam menggunakan uji hipotesis.

Pengaruh Permainan Congklak dan Gatheng Terhadap Kecerdasan Logika Matematika Anak Usia Dini di RA Khairu Ummah 


\section{Perbandingan Nilai Post-test Kecerdasan Logika Matematika Anak Usia 5-6 Tahun di Kelas Matahari dan Melati}

Setelah diketahui tahapan perkembangan kecerdasan logika matematika anak pada tahap awal, setelah itu pada Kelas Matahari dan Kelas Melati diberikan perlakuan. Pada Kelas Matahari akan diberi penerapan dengan permainan congklak, sedangkan pada Kelas Melati diterapkan permainan gatheng. Kemudian, diakhir pertemuan anak-anak kembali diberi post-test. Tujuannya yaitu untuk mengetahui kecerdasan logika matematika anak setelah diterapkannya permainan congklak dan permainan gatheng pada Kelas Matahari dan Kelas Melati. Perbandingan nilai post-test kecerdasan logika matematika anak usia 5-6 tahun di kelas Matahari dan Melati disajikan pada Tabel 5 dan Gambar 3:

Tabel 5. Data Post-test Kecerdasan Logika Matematika di Kelas Matahari dan Melati

\begin{tabular}{|c|l|c|c|}
\hline No & \multicolumn{1}{|c|}{ Statistik } & Kelas Matahari & Kelas Melati \\
\hline $\mathbf{1 .}$ & N & 15 & 15 \\
\hline $\mathbf{2 .}$ & Jumlah Skor & 10.174 & 4.229 \\
\hline $\mathbf{3 .}$ & Rata-rata & 26 & 16,73 \\
\hline $\mathbf{4 .}$ & Simpangan Baku & 1,558 & 1,437 \\
\hline $\mathbf{5 .}$ & Varians & 2,428 & 2,066 \\
\hline $\mathbf{6 .}$ & Maksimum & 28 & 19 \\
\hline $\mathbf{7 .}$ & Minimum & 24 & 15 \\
\hline
\end{tabular}


http://jurnaltarbiyah.uinsu.ac.id/index.php/raudhah

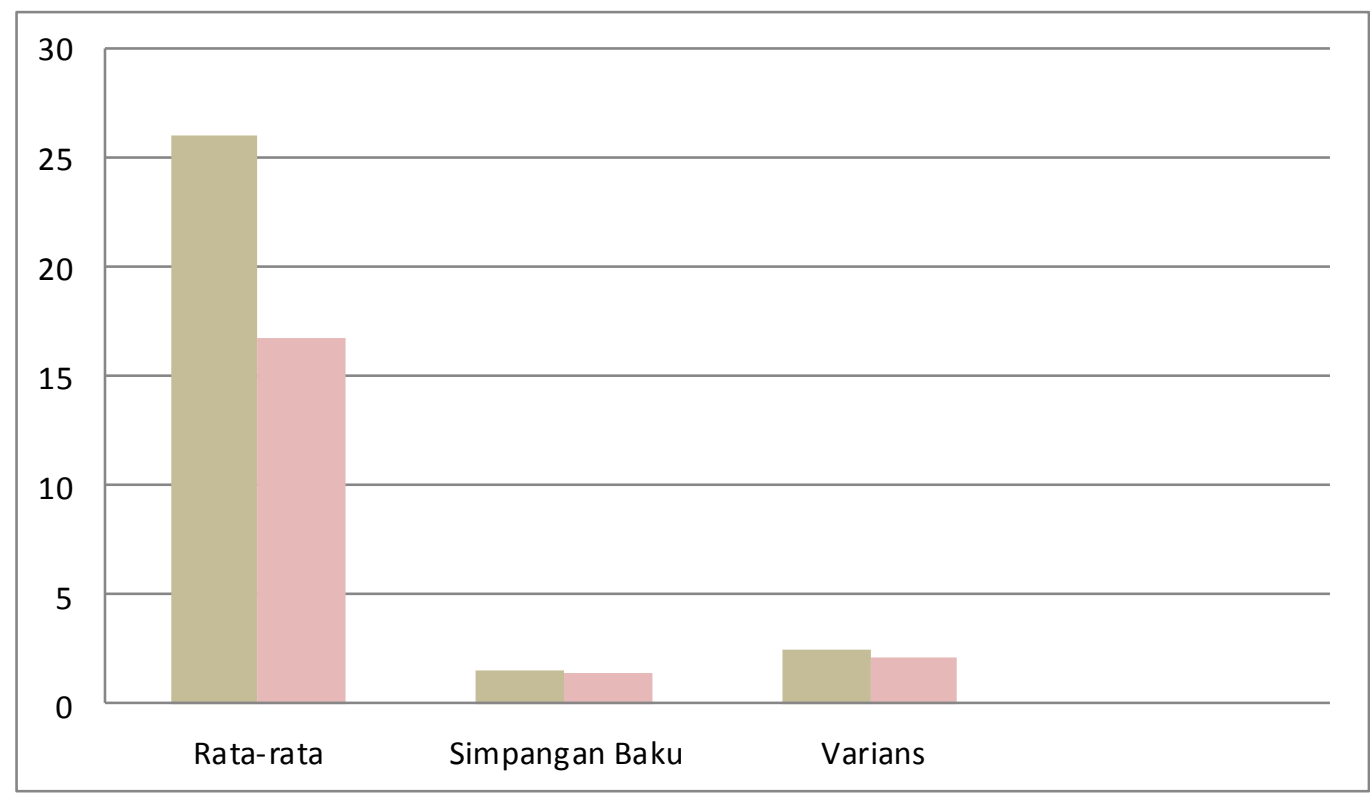

\section{Gambar 3. Data Post-test Kecerdasan Logika Matematika di Kelas Matahari dan Melati}

Tabel 5 menunjukkan bahwa nilai rata-rata di kelas Matahari yaitu 26 atau berkategori berkembang sangat baik (BSB) sedangkan di Kelas Melati yaitu 16,73 atau berkategori berkembang sesuai harapan $(\mathrm{BSH})$, selisih rata-rata pada dua kelas tersebut sebesar 9,37. Simpangan baku di kelas Matahari yaitu 1,558 sedangkan di kelas Melati yaitu 1,437, selisih simpangan baku pada dua kelas tersebut hanya sebesar 0,121. Varians di kelas Matahari yaitu 2,428 sedangkan di kelas Melati 2,066, selisih varians pada dua kelas tersebut hanya sebesar 0,442. Dari gambar 4 juga terlihat bahwa nilai simpangan baku dan varians pada kelas Matahari dan Melati mempunyai tinggi yang hampir sama, namun pada nilai rata-rata terlihat perbedaan tinggi yang mencolok karena selisih nilainya yaitu 9,37. Perbedaan tinggi batang diagram dan nilai rata-rata kecerdasan logika matematika membuktikan bahwa kecerdasan logika matematika anak usia 5-6 tahun mempunyai perkembangan yang berbeda setelah diterapkan treatment yang berbeda, yaitu permainan congklak di kelas Matahari dan permainan gatheng di kelas Melati. Untuk hasil simpulan yang lebih akurat maka data post-test selanjutnya dianalisi menggunakan uji-t. 
http://jurnaltarbiyah.uinsu.ac.id/index.php/raudhah

e-mail: jurnalraudhah@uinsu.ac.id

p-ISSN: 2338-2163

e-ISSN: $2716-2435$

\section{Analisis Data Hasil Penelitian}

\section{a. Uji Normalitas Data}

Uji normalitas menggunakan uji Liliefors bertujuan untuk memberitahu apakah data hasil penelitian telah memiliki sebaran data yang berdistribusi normal atau tidak. Sampel yang berdistribusi normal dikatakan jika dipenuhi $L_{0}<L_{\text {tabel }}$ pada taraf signifikan $\alpha=0,05$. Hasil uji normalitas disajikan pada tabel 6:

Tabel 6. Data Hasil Uji Normalitas

\begin{tabular}{|c|c|c|c|c|c|c|}
\hline \multirow{2}{*}{ Kelas } & \multicolumn{3}{|c|}{ Pre-test } & \multicolumn{3}{c|}{ Post-test } \\
\cline { 2 - 7 } & $\mathrm{L}_{\mathrm{o}}$ & $\mathrm{L}_{\text {tabel }}$ & Keterangan & $\mathrm{L}_{\mathrm{o}}$ & $\mathrm{L}_{\text {tabel }}$ & Keterangan \\
\hline Matahari & 0,198763 & 0,220 & Normal & 0,206129 & 0,220 & Normal \\
\hline Melati & 0,157754 & 0,220 & Normal & 0,16168 & 0,220 & Normal \\
\hline
\end{tabular}

Tabel 6 menunjukkan bahwa uji normalitas pada data pre-test yang berada pada Kelas Matahari diperoleh nilai $\mathrm{L}_{0}(0,198763)<\mathrm{L}_{\text {tabel }}(0,220)$ lalu data pre-test pada Kelas Melati diperolehlah nilai $\mathrm{L}_{0}(0,157754)<\mathrm{L}_{\text {tabel }}(0,220)$. Dari data post-test pada kecerdasan logika matematika pada anak di kelas Matahari diperoleh $\mathrm{L}_{0}(0,206129)<\mathrm{L}_{\text {tabel }}(0,220)$ dan data post-test dari Kelas Melati yaitu $\mathrm{L}_{0}(0,16168)<\mathrm{L}_{\text {tabel }}(0,220)$. Maka dari itu, dapat disimpulkan bahwa distribusi data pre-test dan post-test dalam kecerdasan logika matematika anak melalui permainan congklak pada Kelas Matahari dan permainan congklak pada Kelas Melati berdistribusi normal. Dimana, pada taraf signifikan $\alpha=0,05$ telah memiliki kepercayaan nilai sebesar $95 \%$.

\section{b. Uji Homogenitas}

Uji homogenitas data dimaksudkan untuk mengetahui apakah sampel yang di pakai berasal dari populasi yang bersifat homogen atau tidak. Untuk pengujian homogenitas ini menggunakan rumus fisher yang membutuhkan nilai varians terbesar dan terkecil untuk

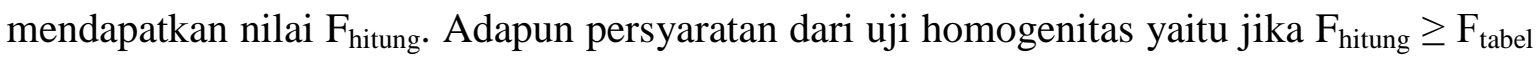
maka $\mathrm{H}_{0}$ ditolak dan $\mathrm{H}_{\mathrm{a}}$ diterima, tetapi jika $\mathrm{F}_{\text {hitung }}<\mathrm{F}_{\text {tabel }}$ maka $\mathrm{H}_{0}$ diterima dan $\mathrm{H}_{\mathrm{a}}$ ditolak dengan derajat kebebasan pembilang $=\left(n_{1}-1\right)$ dan derajat kebebasan penyebut $=\left(n_{2}-1\right)$ dengan taraf nyatanya $\alpha=0,05$. Hasil uji homogenitas disajikan pada tabel 7:

Pengaruh Permainan Congklak dan Gatheng Terhadap Kecerdasan Logika Matematika Anak Usia Dini di RA Khairu Ummah 
http://jurnaltarbiyah.uinsu.ac.id/index.php/raudhah

Tabel 7. Data Hasil Uji Homogenitas

\begin{tabular}{|c|c|c|c|c|c|}
\hline Data & Varians Terbesar & Varians Terkecil & $\mathrm{F}_{\text {hitung }}$ & $\mathrm{F}_{\text {tabel }}$ & Keterangan \\
\hline Pre-test & 1,403 & 1,298 & 1,080 & 2,484 & Homogen \\
\hline Post-test & 1,558 & 1,437 & 1,084 & 2,484 & Homogen \\
\hline
\end{tabular}

Tabel 7 menunjukkan bahwa uji homogenitas pada pre-test nilai varians terbesarnya berjumlah 1,403 varians terkecilnya $1,298, F_{\text {hitung }}(1,080)<F_{\text {tabel }}(2,484)$ sedangkan data post-test varians terbesarnya 1,558 varians yang terkecil $1,437, \mathrm{~F}_{\text {hitung }}$ $(1,084)<\mathrm{F}_{\text {tabel }}(2,484)$ untuk itu, maka disimpulkanlah bahwa distribusi data pre-test dan data post-test dalam kecerdasan logika anak melalui permainan congklak pada Kelas Matahari dan menggunakan permainan gatheng pada Kelas Melati adalah homogenitas.

\section{c. Pengujian Nilai Hipotesis}

Setelah diketahuinya bahwa Kelas Matahari telah berdistribusi normal dan juga homogeny, maka pada tahapan selanjutnya akan dilakukan pengujian hipotesis. Namun, pada pengujian hipotesis ini akan menggunakan uji t. Pengujian uji t ini dilakukan hanya satu pihak sehingga kriteria untuk menerima atau menolak $\mathrm{H}_{0}$ yaitu jika $\mathrm{t}_{\text {hitung }}>$ pada taraf nyatanya $\alpha=0,05 \mathrm{H}_{\mathrm{a}}$ diterima dan ditolak.

Dari hasil uji hipotesis yang pertama telah diperoleh nilai $t_{\text {hitung }}=2,927$ dengan taraf $\alpha=0,05$ yang didapat dari tabel $\mathrm{t}$ pada $\mathrm{dk} 13$ yang diperoleh pada nilai $\mathrm{t}_{\text {tabel }}=2,160$. Karena $t_{\text {hitung }}>t_{\text {tabel }}$ maka $\mathrm{H}_{0}$ ditolak dan $\mathrm{H}_{\mathrm{a}}$ diterima. Jadi, disimpulkan bahwa ada pengaruh permainan congklak terhadap kecerdasan logika matematika anak usia 5-6 tahun di RA Khairu Ummah.

Dari hasil uji hipotesis yang kedua telah didapat nilai $t_{\text {hitung }}=2,839$ dengan taraf nilai $\alpha=0,05$ yang didapat pada tabel $\mathrm{t}$ dengan $\mathrm{dk} 13$ yang diperoleh nilai $\mathrm{t}_{\text {tabel }}=2.160$. karena $t_{\text {hitung }}>t_{\text {tabel }}$ maka $\mathrm{H}_{0}$ ditolak dan $\mathrm{H}_{\mathrm{a}}$ diterima. Jadi, disimpulkan ada pengaruh permainan gatheng terhadap kecerdasan logika matematika anak usia 5-6 tahun di RA Khairu Ummah. 
http://jurnaltarbiyah.uinsu.ac.id/index.php/raudhah

Dari hasil uji hipotesis yang ketiga telah terbukti bahwa terdapat perbedaan yang penting terhadap kecerdasan logika matematika pada anak yang mengikuti kegiatan dengan menggunakan permainan congklak dan permainan gatheng. Untuk itu dapat diketahui melalui hasil analisis data dengan menggunakan uji-t, yang diketahui nilai pada Kelas Matahari diperoleh $t_{\text {hitung }}=2,927$ dengan taraf $\alpha=0,05$ yang didapat pada tablet pada $\mathrm{dk}$ 13 diperoleh nilai $t_{\text {tabel }}=2,160$. Hasil perhitungan tersebut telah menunjukkan bahwa jumlah $t_{\text {hitung }}>t_{\text {tabel }}$ sehingga hasil penelitian menunjukkan signifikan.

Sedangkan, pada nilai yang di Kelas Melati didapat nilai $t_{\text {hitung }}=2,839$ dengan taraf $\alpha$ $=0,05$ yang didapat dari tabel $\mathrm{t}$ pada $\mathrm{dk} 13$ dicapai hasil $\mathrm{t}_{\text {tabel }}=2,160$. Hasil perhitungan tersebut telah menunjukkan bahwa $t_{\text {hitung }}>t_{\text {tabel }}$ sehingga hasil penelitian ini signifikan. Berdasarkan deskripsi data hasil penelitian, maka kelompok anak yang diberi permainan congklak telah memiliki kecerdasan logika matematika yang lebih tinggi apabila dibandingkan dengan anak yang permainan gatheng pada usia 5-6 tahun di RA Khairu Ummah.

Tabel 8. Data Hasil Uji Hipotesis

\begin{tabular}{|c|c|c|c|c|}
\hline No & Uji Hipotesis & $\mathbf{T}_{\text {hitung }}$ & $\mathbf{T}_{\text {tabel }}$ & Kesimpulan \\
\hline $\mathbf{1}$ & Kelas Matahari & 2,927 & 2,160 & $\mathrm{~T}_{\text {hitung }}>\mathrm{T}_{\text {tabel }}$ \\
\hline $\mathbf{2}$ & Kelas Melati & 2,839 & 2,160 & $\mathrm{~T}_{\text {hitung }}>\mathrm{T}_{\text {tabel }}$ \\
\hline
\end{tabular}

Sedangkan, hasil analisis data dengan menggunakan uji-t, telah diketahui bahwa nilai post-test dari Kelas Melati dan Kelas Matahari nilai $t_{\text {hitung }}=17,16$ dengan taraf $\alpha=$ 0,050 didapat pada tabel $\mathrm{t}$ pada $\mathrm{dk} 28$ diperoleh nilai $\mathrm{t}_{\text {tabel }}=2,048$. Hasil perhitungan tersebut menunjukkan bahwa $t_{\text {hitung }}>t_{\text {tabel, }}$ sehingga hasil penelitian adalah signifikan. Berikut disajikan dalam bentuk tabel hasil perhitungan uji hipotesis nilai posttest Kelas Matahari dan Kelas Melati. 
http://jurnaltarbiyah.uinsu.ac.id/index.php/raudhah

e-mail: jurnalraudhah@uinsu.ac.id

p-ISSN: 2338-2163

e-ISSN: 2716-2435

Tabel 9. Data Hasil Perhitungan Uji Hipotesis Post-test Kelas Matahari Dan Kelas

Melati

\begin{tabular}{|c|c|c|c|c|l|}
\hline \multicolumn{2}{|c|}{ Skor Rata-Rata Nilai Post-test } & \multirow{2}{*}{$\mathrm{DK}$} & \multirow{2}{*}{$\mathrm{T}_{\text {hitung }}$} & $\mathrm{T}_{\text {tabel }}$ & Kesimpulan \\
\cline { 1 - 5 } Kelas Matahari & Kelas Melati & & & & \\
\hline 34 & 29 & 28 & 17,16 & 2,048 & $\mathrm{t}_{\text {hitung }}>\mathrm{t}_{\text {tabel }}$ \\
\hline
\end{tabular}

Tabel 9 menunjukkan bahwa rata-rata skor hasil dari kecerdasan logika matematika. Rata-rata nilai post-test anak yang telah mengikuti kegiatan melalui permainan congklak yaitu 34 yaitu yang berada pada kategori tinggi sedangkan rata-rata nilai post-test terhadap kecerdasan logika matematika anak melalui permainan gatheng yaitu 29 yakni yang berada pada kategori lebih rendah.

Berdasarkan dari temuan pada penelitian ini telah menunjukkan bahwa ada pengaruh permainan congklak terhadap kecerdasan logika matematika pada anak usia 5-6 tahun di RA Khairu Ummah. Hal ini ditunjukkan dari hasil analisis data dengan menggunakan uji-t, yang diketahui nilai post-test Kelas Matahari diperoleh nilai $t_{\text {hitung }}=17,16$ dan didapat pada tabel t pada df 28 diperoleh nilai $t_{\text {tabel }}=2,048$. Hasil perhitungan tersebut menunjukkan bahwa $t_{\text {hitung }}>t_{\text {tabel}}$, sehingga hasil penelitian signifikan. Hasil penelitian ini sejalan dengan penelitian yang dilakukan oleh (Niyati et al., 2016) bahwa permainan tradisional congklak dapat meningkatkan kecerdasan logika matematika anak, dan disarankan kepada guru untuk menjadikan permainan tradisional congklak sebagai alternatif pembelajaran. Hasil penelitian (Miswara et al., 2018) memaparkan bahwa sebelum diberikan permainan congklak sebagian besar kemampuan berhitung anak berada dalam kategori cukup baik sebanyak 14 anak dan sesudah diberikan permainan congklak maka kemampuan berhitung sebagian anak berkategori baik sebanyak 18 anak. Penelitian (Ramadhani et al., 2018) membuktikan bahwa setelah menggunakan permainan congklak maka kecerdasan logis matematis anak telah berkembang, dan mematuhi peraturan permainan, dengan mendapatkan 3 atau 4 bintang sebanyak 13 orang anak.

Pengaruh Permainan Congklak dan Gatheng Terhadap Kecerdasan Logika Matematika Anak Usia Dini di RA Khairu Ummah 
http://jurnaltarbiyah.uinsu.ac.id/index.php/raudhah

e-mail: jurnalraudhah@uinsu.ac.id

p-ISSN: 2338-2163

e-ISSN: $2716-2435$

\section{SIMPULAN DAN SARAN}

Temuan penelitian menyimpulkan beberapa hal, yaitu: (1) ada pengaruh permainan congklak terhadap kecerdasan logika matematika anak usia 5-6 tahun di RA Khairu Ummah; (2) ada pengaruh permainan gatheng terhadap kecerdasan logika matematika anak usia 5-6 tahun di RA Khairu Ummah; dan (3) terdapat perbedaan pengaruh antara permainan congklak dengan permainan gatheng terhadap kecerdasan logika matematika anak usia 5-6 tahun di RA Khairu Ummah.

Penelitian ini juga menyampaikan saran kepada pihak terkait atau yang berkenaan langsung dengan proses penelitian ini, yaitu: (1) kepada kepala sekolah disarankan agar dapat menerapkan permainan congklak secara sering kepada anak agar kecerdasan logika matematika yang ada pada anak dapat semakin meningkat; (2) kepada guru, disarankan agar dalam waktu satu minggu haruslah ada permainan congklak, karena permainan congklak ini mampu untuk mengasah kognitif dan fisik motorik anak; (3) kepada orang tua disarankan agar mampu untuk melatih anak kembali dirumah dengan menerapkan permainan congklak kepada anak, karena hal ini mampu menstimulus kognitif anak sehingga kecerdasan logika matematika yang ada pada diri anak akan terasah dengan baik melalui beberapa permainan yang ia dapat dari orang tuanya; dan (4) kepada peneliti selanjutnya, diharapkan agar nantinya dapat melanjutkan penelitian ini, menguasai perkembangan anak usia dini melalui kegiatan pembelajaran yang lebih menarik dan meyakinkan hasil penelitiannya dengan menggunakan berbagai referensi yang lebih akurat dan terpercaya. Sehingga hal ini dapat menyajikan referensi dalam permainan congklak.

\section{DAFTAR PUSTAKA}

Maisarah. (2016). Perbedaan Pengaruh Model Pembelajaran Hands-On Mathematics dan Realistic Mathematics Education Terhadap Kemampuan Pemahaman Relasional dan Mathematics Anxiety Siswa SDIT Khairul Imam. Universitas Negeri Medan.

Maisarah. (2019). Metodologi Penelitian Pendidikan Pendekatan Kuantitatif. Medan:

Akasha Sakti.

Miswara, A., Wiyono, J., \& Ariani, N. L. (2018). Pengaruh Permainan Congklak Terhadap

Pengaruh Permainan Congklak dan Gatheng Terhadap Kecerdasan Logika Matematika Anak Usia Dini di RA Khairu Ummah 
http://jurnaltarbiyah.uinsu.ac.id/index.php/raudhah

e-mail: jurnalraudhah@uinsu.ac.id

p-ISSN: 2338-2163

e-ISSN: $2716-2435$

Peningkatan Kemampuan Berhitung Anak Usia 4-6 Tahun di TK Dharma Wanita

Persatuan 02 Malang. Jurnal Nursing News, 3(1).

Niyati, M. D., Kurniah, N., \& Syam, N. (2016). Meningkatkan Kecerdasan Logika

Matematika Melalui Permainan Tradisional Congklak. Jurnal Ilmiah Potensia, 1(2).

Ramadhani, D., Fakhriah, \& Yuhasriati. (2018). Mengembangkan Kecerdasan Logis

Matematis Anak Melalui Permainan Congklak Angka di TK IT Permata Sunnah

Banda Aceh. Jurnal Ilmiah Mahasiswa Penddiikan Anak Usia Dini, 3(4).

Sugiyono. (2017). Metode Penelitian Pendidikan Pendekatan Kuantitatif, Kualitattif dan

RnD. Bandung: Alfabeta.

Pengaruh Permainan Congklak dan Gatheng Terhadap Kecerdasan Logika Matematika Anak Usia Dini di 